\title{
AC 2011-2094: INTEGRATION OF HYDROGEN FUEL CELL TECHNOL- OGY TO UNDERGRADUATE EDUCATION IN EET PROGRAMS
}

\author{
Abed El Hameed El Madwar, University of Northern Iowa
}

Hameed Madwar is currently a doctorate student in the Industrial Technology Program at the University of Northern Iowa expecting to graduate on May 2011. He has a B.S in Electrical and Computer Engineering and a Master degree in Industrial Management. His research interests are in the area of industrial Wireless Sensor Networks (WSN) and Virtual Manufacturing applications. He has more than three years of industrial experience in Manufacturing Technology and four years as a teaching assistant in the areas of Circuits Designs, Renewable Energy, Electrical Power and Machinery.

\section{kenan baltaci, University of Northern Iowa}

Reg Recayi Pecen, University of Northern Iowa

Dr. Pecen holds a B.S.E.E. and an M.S. in Controls and Computer Engineering from the Istanbul Technical University, an M.S.E.E. from the University of Colorado at Boulder, and a Ph.D. in Electrical Engineering from the University of Wyoming (UW, 1997). He has served as graduate assistant and faculty at the UW, and South Dakota State University. He is currently a professor and program coordinator of Electrical Engineering Technology program at the University of Northern Iowa. He is also serving as a graduate program coordinator at the Department of Industrial Technology. He serves on UNI Energy and Environment Council, CNS Diversity Committee, University Diversity Advisory Board, and Graduate College Diversity Task Force Committees. His research interests, grants, and publications are in the areas of AC/DC Power System Interactions, distributed energy systems, power quality, and grid-connected renewable energy applications including solar and wind power systems. He is a member of ASEE, IEEE, Tau Beta Pi National Engineering Honor Society, and ATMAE. Dr. Pecen was recognized as an Honored Teacher/Researcher in "Who's Who among America's Teachers" in 2004-2009. Dr. Pecen is a recipient of 2010 Diversity Matters Award at the University of Northern Iowa for his efforts on promoting diversity and international education at UNI. He was also nominated for 2004 UNI Book and Supply Outstanding Teaching Award, March 2004, and nominated for 2006, and 2007 Russ Nielson Service Awards, UNI. Dr. Pecen is an Engineering Technology Editor of American Journal of Undergraduate Research (AJUR). He has been serving as a reviewer on the IEEE Transactions on Electronics Packaging Manufacturing since 2001. Dr. Pecen has served on ASEE Engineering Technology Division (ETD) in Annual ASEE Conferences as a paper reviewer, session moderator, and co-moderator since 2002. He is serving as a program chair on American Society of Engineering Education (ASEE) Energy Conversion and Conservation Division in 2010-2011. He is also serving on advisory boards of International Sustainable World Project Olympiad (isweep.org) and International Hydrogen Energy Congress. Dr. Pecen is representing UNI at Wind Energy Alliance, IWEA, and IAwind.org. Dr. Pecen has been teaching Building Operator Certificate (BOC) workshops for the Midwest Energy Efficiency Alliance (MEEA) since 2007. www.uni.edu/pecen www.uni.edu/indtech/eet 


\title{
Integration of Hydrogen Fuel Cell Technology to Undergraduate Education in EET Programs
}

\begin{abstract}
The depleting fossil fuel resources and increasing air pollution are leading to the research and development of alternate energy generation. Hydrogen fuel cells are one of the most promising alternate energy supplies. The Hampden Fuel Cell Technology Trainer H-FCTT-1 allows students to create a grid independent power supply that uses only hydrogen as its fuel. The system introduces students to the fuel cell power supply technology as an environmentally friendly method of generating power directly from a hydrogen reaction. This paper describes the integration of the H-FCTT-1 hydrogen fuel cell trainer in the undergraduate class titled "Introduction to Circuits" in the Electrical Engineering Technology (EET) program at the University of Northern Iowa. The learning objectives are to run three experiments and determine: (1) the voltage-current and power-current characteristics, (2) voltage, current, and overall efficiency of the system, (3) maximum power versus optimum efficiency. Students applied the skills acquired in the "Introduction to Circuits" to run the H-FCTT1 trainer and differentiate between electronic and electrical loads. In addition, they are introduced to an alternative energy source that converts chemical energy into the electricity directly.
\end{abstract}

\section{Introduction}

The design and implementation of hydrogen fuel cell systems in education allow students to understand the alternative sources of energy and consider a grid independent power supply that uses Hydrogen as an alternate source of fuel. The utilization of the fuel cell system not only allows students to think of other sources of energy, but also considers the improvements of computer hardware and data acquisition systems to design systems upon certain criterion. Many data acquisition systems have been developed through a third party acquisition system that requires programming interface and design ${ }^{1}$. For this work, embedded control software was found to be a convenient tool to meet the needs of fuel cell instructors to work with students on hydrogen fuel cell experiments. The software is characterized by its ease of use and can alternatively control the fuel cell trainer's physical knobs. It can also monitor and log all system parameters and include an extensive historical database thus allowing users to perform offline analysis. Additionally, the data acquisition system has the capability of graphing the resulting voltage, current, power, and system. These features allow instructors to teach fuel cell systems on two levels: the first is designed for introductory students who have basic knowledge on electrical circuits and are required to perform the connections. The second level is designed for either graduate students or advanced level EET students who have knowledge and past experience with fuel cell and need to focus on the overall system results.

\section{Hydrogen Fuel Cell Technology}

The concerns about fuel depletion and climate change have led to rapid increase in research for alternative energy technologies. A fuel cell converts chemical reactions to direct current (DC) electricity directly. Compared with combustion, fuel cells attain high efficiency because they do not have to convert heat to mechanical energy as the case of producing electricity from chemical energy ${ }^{1}$. Thus, hydrogen fuel cell is one form of alternative energy that requires a diverse area of 
engineering. It is important to note that alternative energy was not considered as part of the engineering courses until recently. The increasing attention towards fuel cell technologies, the need to develop more research, and the desire to train more specialists, caused the engineering education to adopt alternative energy studies.

Every fuel cell requires a type of fuel to convert the energy produced in chemical reaction to electrical energy. The hydrogen fuel cell uses the hydrogen gas $\left(\mathrm{H}_{2}\right)$ as the fuel needed for this conversion. Each cell consists of an electrolyte located between two electrodes, an anode and a cathode. When the hydrogen is forced to come in contact with the anode, a catalyst separates the hydrogen molecule into hydrogen ions and electrons. Simultaneously, when the oxygen drawn from outside air comes in contact with the cathode, the catalyst separates the oxygen molecule into two oxygen atoms and strong negative charges. The negative charges at the cathode attract the hydrogen ions through the electrolyte. Since the electrolyte conducts only protons, it will force the electrons to take another path through the external circuit to produce electricity. The hydrogen ions, electrons and oxygen atoms combine at the cathode in an exothermic reaction to produce water molecules ${ }^{2}$ :

$$
\mathrm{O}_{2}+4 \mathrm{e}^{-}+4 \mathrm{H}^{+}=2 \mathrm{H}_{2} \mathrm{O}
$$

As mentioned earlier, each cell consists of two anode, cathode, and electrolyte. Each cell can produce an approximate voltage of 0.7 Volts. Therefore, depending on the applications, fuel cells must be combined in series to form a fuel cell stack that generates the necessary power ${ }^{3}$. Generally, the fuel stack is considered to be a small part of the overall system that includes a cooling system, a voltage converter, electronic load, and electric load.

The hydrogen fuel cell technology is characterized by its efficiency, simplicity, low emissions, and silence ${ }^{3}$. Hydrogen fuel cells are considered to have zero emissions and are eco-friendly alternative source of energy. In comparison with conventional fuel systems, hydrogen fuel cell generates power through a chemical reaction and the only fuel and products are hydrogen, oxygen, and water vapor. The efficiency of hydrogen fuel cell is higher than traditional combustion engines ${ }^{1-3}$. In addition to the fact that hydrogen can be accessed through abundant resource of $\mathrm{H}_{2} \mathrm{O}$ as oppose to depleting fossil fuels, hydrogen fuel cells have the potential to lead the "world fuel and energy vector" 3 . Therefore, fuel cell technologies have the capability to be customized to fit diverse areas of applications such as portable electronics, transportation, and distributed power generation depending on the type of the fuel cell.

\section{Comparison of Fuel Cells with other Sources of Energy}

Fuel cells differ from batteries by nature and by use. Although, both use anode and cathode to generate power, batteries consist of metals that cannot be usable when fully consumed. Whereas the fuel cells are based on chemical reactions and can continue to operate as long as reactants are supplied. The difference between fuel cell and internal combustion engines is mainly the method of reaction. Internal combustion engines' reaction is electromechanical that generates mechanical energy; the fuel cell reaction is an electrochemical process that produces electrical energy ${ }^{4}$. Since fuel cells do not use combustion in the reaction as the case in combustion engines, the 
efficiency generated is significantly higher and they behave like batteries at partial load that is less variation in efficiency over the entire period. The fact that fuel cells can operate at better efficiency than other sources of energy and having plenty of fuel sources have promised an effective solution for various types of applications in the transportation industry, distributed power, and electronic devices.

\section{Recent Fuel Cell Applications}

Fuel cell technology has been proven as a potential solution for the increasing demand of expanding distributed power generation and to the depletion of fossil fuels. It has been estimated that the US power requirements by the year 2020 will be three times as of $2000^{5}$. The US Department of Energy study ${ }^{6}$ shows that fuel cell distributed power generation has the lowest dependency on petroleum energy because the natural-gas-based generation technologies consume insignificant amount of petroleum due to the recovery and processing of the natural gas. In Europe, it has been estimated ${ }^{7}$ that per life cycle assessment, each $\mathrm{kWh}$ of electricity produced by fuel cell technology can reduce $\mathrm{CO}_{2}$ emissions by more than $40 \%$ compared to those from fossil fuel.

Because fuel cells can be significantly small, the technology is also very attractive for use in small portable consumer electronics. There are many examples of this use. the Ballard fuel cell military backpack can operate for 20 hours ${ }^{8}$. Recently, Horizon announced the launching of the pocket-size fuel cell power plant for portable electronics that delivers 1.5 to $2 \mathrm{~W}$ continuous power and stores up to $12 \mathrm{Wh}$ of total energy ${ }^{9}$. This product targets small power electronics such as cell phones, smart phones, MP3 players, etc.

One major disadvantage of fuel cells in the transportation applications is the long start-up time and slow power response ${ }^{10}$ that makes fuel cells have lower efficiencies during sharp accelerations or at low-speed driving as shown in Figure 1. This explains the production of the fuel cell hybrid electric drive vehicles to overcome those issues. For example, Honda released its zero emission automobile FCX-C4 that has enhanced start-up time and improved acceleration ${ }^{8}$.

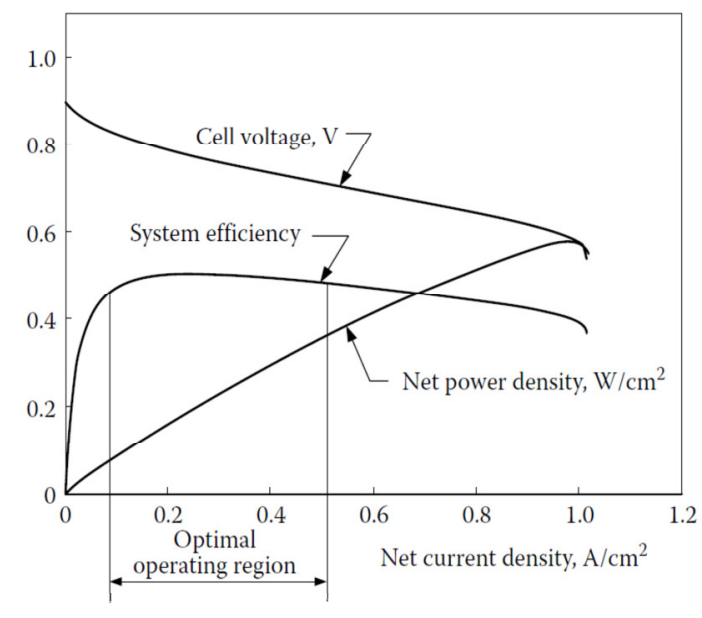

Figure 1: Basic operating characteristics of Fuel Cell ${ }^{10}$ 


\section{Project Description}

The Hampden Model HH-FCTT-1 Fuel Cell Technology trainer was purchased by the department of Industrial Technology at the University of Northern Iowa for the use of laboratory activities as well as general recruitment tool. This trainer was selected because of its simplicity. The trainer contains an interfacing program package that does not need any major configurations. Thus, students can easily start experiments without being confused with the details of interfacing and do need background in interface programming. Students can either interface with the trainer directly, or use the control software when needed. The fuel cell component in this system is the FC50 Module.

\section{Fuel Cell Module FC50}

The fuel cell stack consists of 10 single cells connected in series. The hydrogen is supplied through a quick coupler connection and can be controlled by the user from the hydrogen container. There are three choices of hydrogen supply: (1) compressed gas cylinder, (2) metal hydride storage with refilling kit, (3) hydrogen generator with metal hydride storage. A fan is attached at the top of the fuel cell stack to provide air for both the chemical reaction and for cooling purposes. The fans can be controlled physically by the knob or by the control software if the FC50 module connected to the computer via the cable RS232. The FC50 communicates with the load modules EL 200 and VC100 if attached using the RS485 cable. The function of the Electronic Module EL 200 shown in Figure 3 is to convert electrical energy into heat using regulated resistance. It is important to increase the electronic load gradually to avoid damaging cells that are not thoroughly wet ${ }^{1}$. As seen in Figure 4, the Voltage Converter VC100 main functions are to operate the trainer as a grid independent power supply by providing "power to the system during the 10 seconds starting sequence until the fuel cell itself can generate power" 1 and control the fan power by providing a constant $12 \mathrm{~V} \mathrm{DC}$.

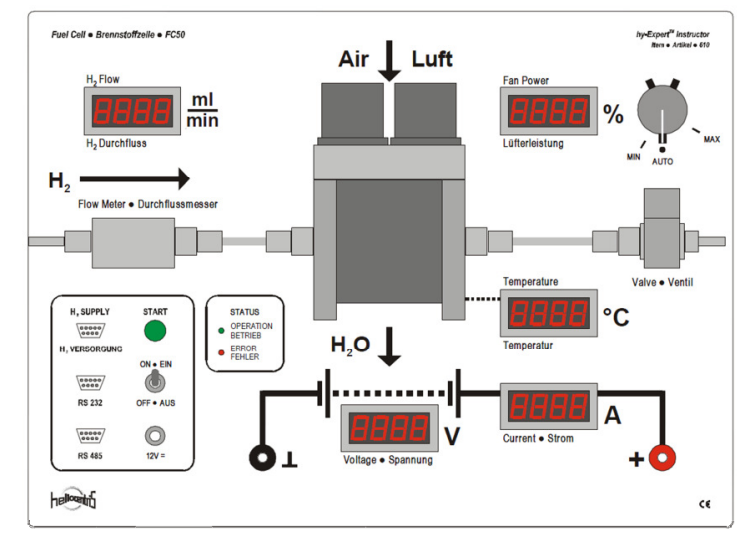

Figure 2: Fuel Cell Module FC50 ${ }^{1}$ 


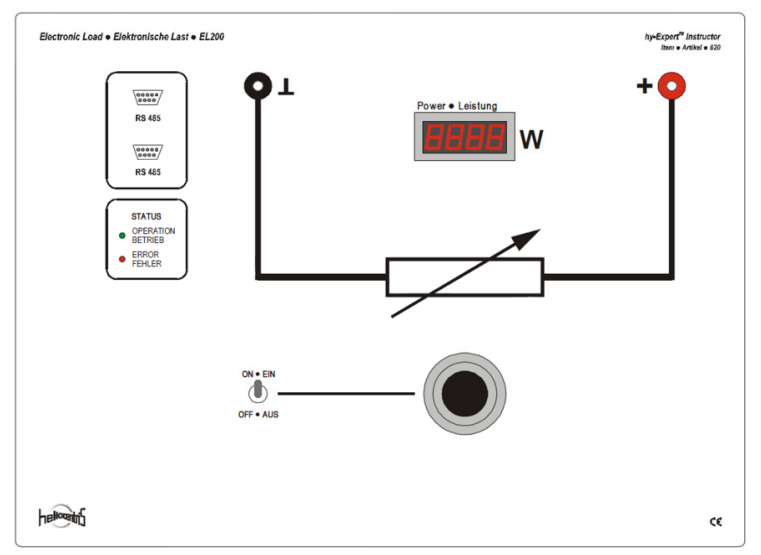

Figure 3: Electronic Load EL200 ${ }^{1}$

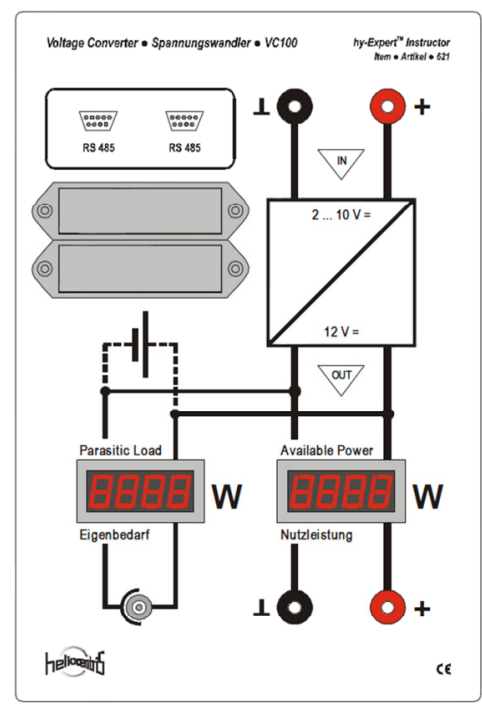

Figure 4: Voltage Converter VC100 ${ }^{1}$

\section{Experiments}

Three laboratory exercises were introduced at the end of the Electric Circuit course that required connecting the fuel cell system as shown in Figure 5. All students were undergraduate majors in the EET program. A graduate assistant supervised twenty students to perform the experiment. The students were assigned as teams to perform the experiment on ten sessions that took about two days. Each team consisted of two to three students. Although this system was not introduced in detail in the lectures, particularly the chemistry of the Hydrogen fuel cell, the authors believe it is a potential educational tool to extend the knowledge learned in the classroom to nontraditional lab activities. This activity aims to meet the following program outcomes of the Electrical Engineering Program at the University of Northern Iowa ${ }^{11}$ : 
1- Students will possess problem solving skills involving analysis, design, and simulation of laboratory experimentation with applications to electrical and electronic components, circuits and systems.

2- Students will have an ability to design and carry out experiments and tests, analyze and interpret data, and make iterative improvements by using safe and technically correct laboratory methods.

3- Students will have knowledge of fundamental principles of science and mathematics and apply them to solve practical problems of engineering technology.

4- Students will produce clear, precise and effective technical documents and oral presentations for both professional and general audience with the help of modern information technologies.

5- Students will collaborate with each other in laboratory and classroom settings to work effectively in teams.

The main objectives of this fuel cell laboratory are listed as follows:

1- To introduce a clean electrical power generation using Hydrogen Fuel Cells.

2- To introduce state-of-the-data acquisition and instrumentation for Hydrogen Fuel cells systems.

3- To expose students to new available technologies

4- To apply knowledge and skills of Electrical Circuits to non-traditional applications.

Understanding each subsystem of the Hydrogen fuel cell system will allow students to perform the tasks of this experiment. Twenty students in the class participated in the experiment. The students were asked to complete the following tasks:

1- Check the safety rules provided by the Hampden Model H-FCTT-1

2- Read the appropriate provided information about the trainer system to get familiar with the equipments.

3- Run the trainer with the supervision of the instructor with no load connection to make sure that the system is running.

4- Follow the instructions provided in the lab manual to run the system.

5- Students must understand and perform the system wiring correctly in order to meet the activity objectives.

6- Collect information either by the software or manually from the trainer interface.

7- Analyze the generated data and perform the proper calculations to calculate the system efficiency.

8- Generate a technical report of the results demonstrating the charts of the current, voltage, and system efficiency. 


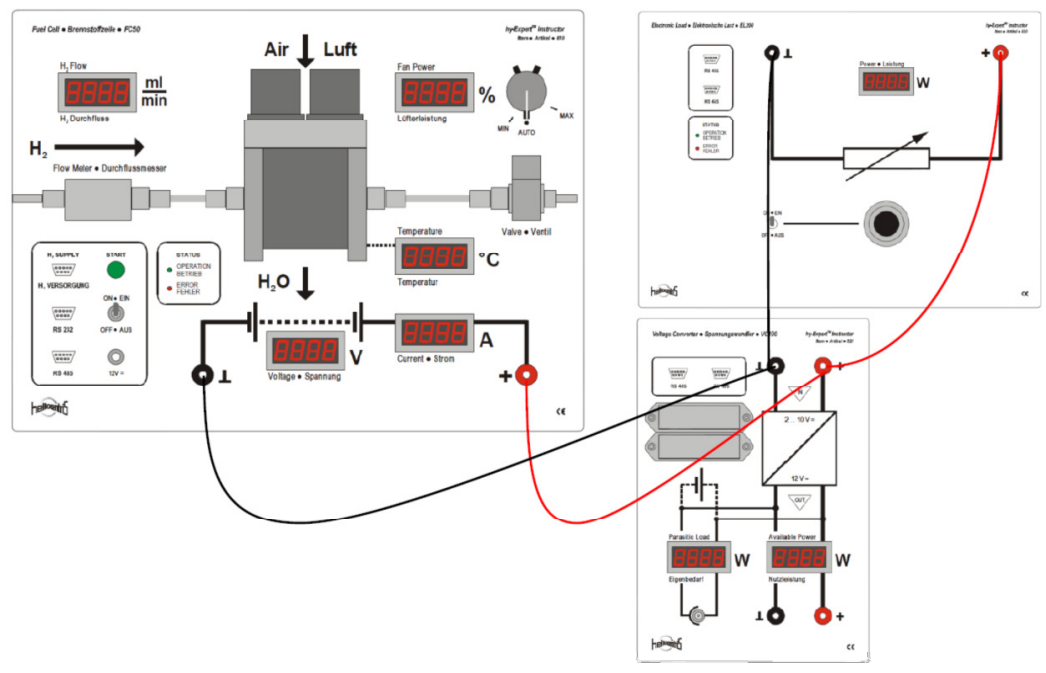

Figure 5: Fuel Cell System Connection ${ }^{1}$

\section{Current Measurement}

One of the major challenges that students struggled with was calculating the current efficiency. The current efficiency as explained in the Hampden student manual ${ }^{(1)}$ is determined using the following equation:

$$
\eta_{I}(I)=\frac{I}{I_{t h}}
$$

Where $\mathrm{I}$ is the measured current and $\mathrm{I}_{\mathrm{th}}$ is the calculated current that can be found using this formula:

$$
I_{t h}=\frac{(V \cdot F \cdot z)}{V_{m} \cdot n}
$$

$\mathrm{V}$ is the volume flow of hydrogen in the stack. F which is the Faraday's constant was given as $96,485 \mathrm{Cmol}^{-1}$. $\mathrm{Z}$ is the number of electrons per particle conversion that is $2 . \mathrm{V}_{\mathrm{m}}$ is the molar volume at temperature $275.15 \mathrm{~K}$ which is 32 Fahrenheit and can be deduced using the formula:

$$
V m=R T / P
$$

$\mathrm{R}$ is provided ${ }^{(1)}$ to be $0.820571 \mathrm{tm} / \mathrm{mol} \mathrm{K}$. Whereas $\mathrm{P}$ is the permissible hydrogen input pressure that ranges between 0.4 and 0.8 bar gauge. Most students were confused because many of the terms provided by the lab manual ${ }^{8}$ were constants except for the hydrogen pressure that can vary according to the read on gauge. Therefore, a value of 1.776 was selected to be the nominal value through all the experiments as the Teacher Manual suggested ${ }^{1}$. 
In general, it was noticed that students were able to carry out all the measurements with no major difficulties. They were able to do all the connecting wires and establishing a block diagram similar to Figure 6.

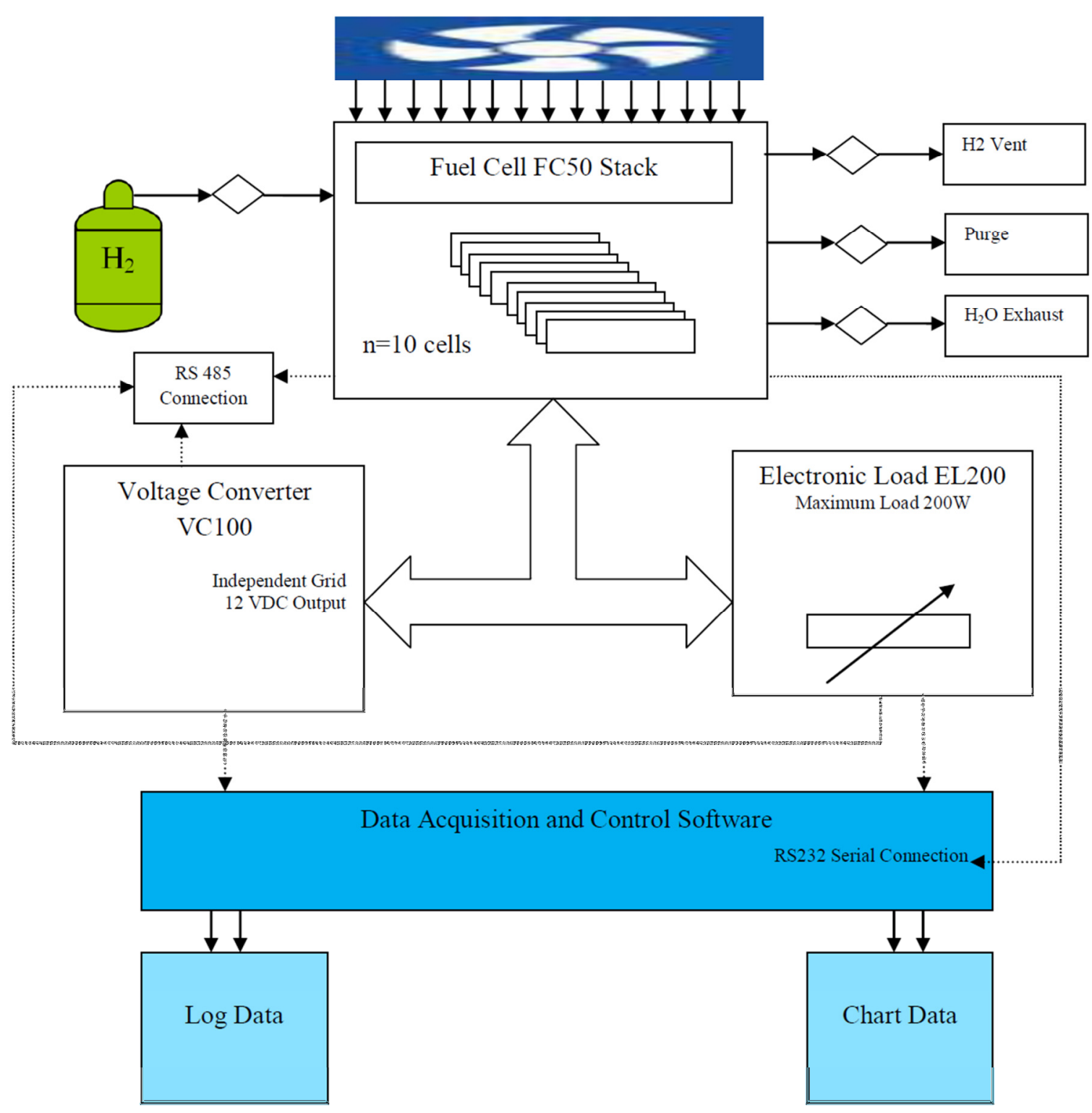

Figure 6: Hampden H-FCTT-1 Hydrogen fuel cell trainer functional block diagram

\section{System Efficiency Case Study}

This case study is to determine the efficiency of the hydrogen fuel cell system represented in Figure 7. The purpose of this case study is to report measurable data on fuel cell trainers. Fuel cell trainers can be used as an educational model for students to practice their mathematical skills 
and engineering knowledge. Table 1 represents the data collection on current, voltage, and hydrogen flow. Table 2 shows the efficiencies of voltage, current, and overall systems calculated according to the following formulas:

Voltage Efficiency:

$$
\eta_{U}(I)=\frac{V(I)}{V_{\text {ref }}}
$$

Current Efficiency:

$$
\eta_{I}(I)=\frac{I}{I_{t h}}
$$

System Efficiency:

$$
\eta_{E}(I)=\eta_{U}(I) \cdot \eta_{I}(I)
$$

It should be noted that $\mathrm{V}_{\text {ref }}$ was selected to be 1.23 volts by Manufacturer design ${ }^{1}$.

Table 1: Measured Current, Voltage, Hydrogen Flow Rate

\begin{tabular}{|c|c|c|}
\hline Current (A) & Voltage (V) & $\begin{array}{l}\text { Flow Rate } \\
\left(\mathrm{VH}_{2} / \mathrm{ml} \mathrm{min}^{-1}\right)\end{array}$ \\
\hline 0.00 & 7.1 & 0 \\
\hline 1.5 & 6.93 & 104 \\
\hline 2 & 6.65 & 139 \\
\hline 2.5 & 6.44 & 175 \\
\hline 3 & 6.31 & 211 \\
\hline 3.5 & 6.2 & 244 \\
\hline 4.0 & 6.09 & 278 \\
\hline 4.5 & 5.99 & 313 \\
\hline 5 & 5.84 & 349 \\
\hline 5.5 & 5.77 & 385 \\
\hline 6.5 & 5.64 & 419 \\
\hline 7 & 5.52 & 455 \\
\hline 7.5 & 5.4 & 494 \\
\hline 8 & 5.3 & 522 \\
\hline 8.5 & 5.19 & 564 \\
\hline 9 & 5.23 & 597 \\
\hline 9.5 & 5.11 & 637 \\
\hline 10.0 & 5.01 & 668 \\
\hline
\end{tabular}


Table 2: Calculated Voltage, Current, and Overall System Efficiencies

\begin{tabular}{|c|c|r|r|r|r|}
\hline Current (A) & Voltage (V) & \multicolumn{1}{l|l}{$\begin{array}{l}\text { I } \mathrm{I}_{\mathrm{th}}(\mathrm{A}) \\
\text { Voltage } \\
\text { Efficiency }\end{array}$} & $\begin{array}{l}\text { lurrent } \\
\text { Efficiency }\end{array}$ & $\begin{array}{l}\text { Overall } \\
\text { Efficiency }\end{array}$ \\
\hline 0.00 & 7.1 & 0.00 & 5.7724 & 0.0000 & 0.0000 \\
\hline 1.5 & 6.93 & 2.65 & 5.6341 & 2.6504 & 3.1887 \\
\hline 2 & 6.65 & 3.54 & 5.4065 & 3.5424 & 3.0525 \\
\hline 2.5 & 6.44 & 4.46 & 5.2358 & 4.4598 & 2.9350 \\
\hline 3 & 6.31 & 5.38 & 5.1301 & 5.3773 & 2.8621 \\
\hline 3.5 & 6.2 & 6.22 & 5.0407 & 6.2183 & 2.8372 \\
\hline 4.0 & 6.09 & 7.08 & 4.9512 & 7.0847 & 2.7954 \\
\hline 4.5 & 5.99 & 7.98 & 4.8699 & 7.9767 & 2.7473 \\
\hline 5 & 5.84 & 8.89 & 4.7480 & 8.8941 & 2.6692 \\
\hline 5.5 & 5.77 & 9.81 & 4.6911 & 9.8116 & 2.6296 \\
\hline 6.5 & 5.64 & 10.68 & 4.5854 & 10.6781 & 2.5765 \\
\hline 7 & 5.52 & 11.60 & 4.4878 & 11.5955 & 2.5157 \\
\hline 7.5 & 5.4 & 12.59 & 4.3902 & 12.5894 & 2.4411 \\
\hline 8 & 5.3 & 13.30 & 4.3089 & 13.3030 & 2.4293 \\
\hline 8.5 & 5.19 & 14.37 & 4.2195 & 14.3734 & 2.3485 \\
\hline 9 & 5.23 & 15.21 & 4.2520 & 15.2143 & 2.3755 \\
\hline 9.5 & 5.11 & 16.23 & 4.1545 & 16.2337 & 2.3032 \\
\hline 10.0 & 5.01 & 17.02 & 4.0732 & 17.0238 & 2.2730 \\
\hline
\end{tabular}

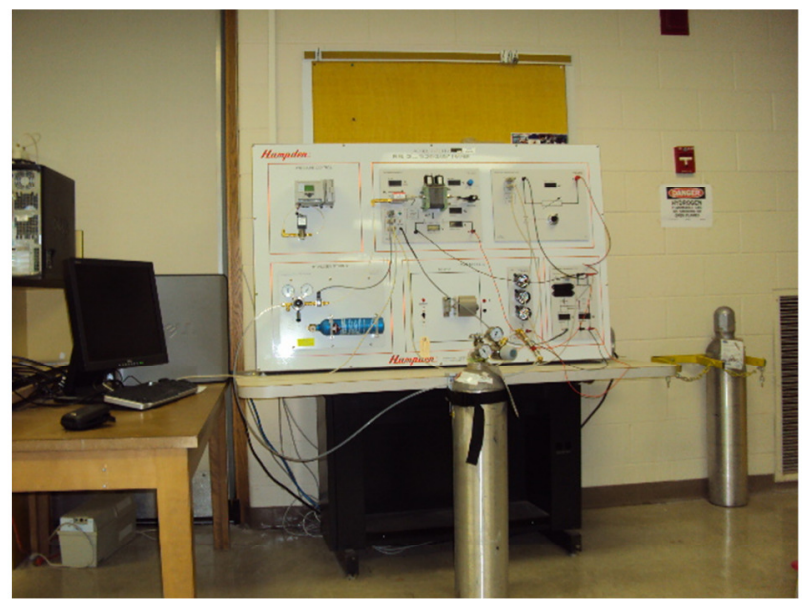

Figure 7: Hampden H-FCTT-1 Fuel Cell

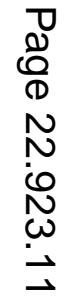




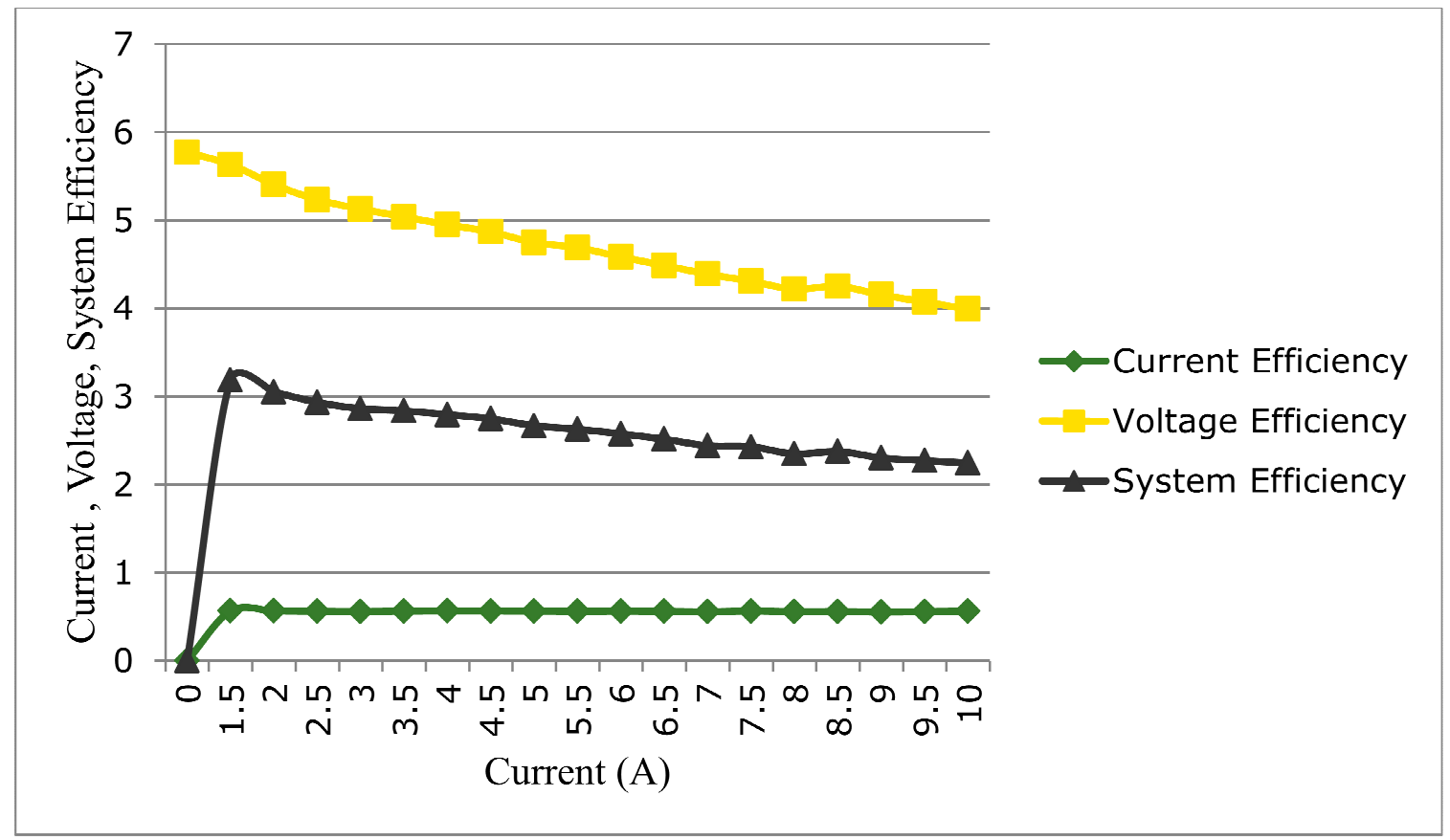

Figure 8: Characteristics of Current, Voltage, and System Efficiency

\section{Student Survey}

After completing the experiment, students were asked to participate in a survey to measure their satisfaction on the hydrogen fuel cell activity and alternative energy applications. Students' response to the following questionnaire is represented in Figure 9.

1- Have you found the lab useful to improve your knowledge on alternative energy applications?

2- Have you found the lab useful to improve your knowledge on energy efficiency?

3- Are mathematical relations and calculations selected in this lab appropriate for your skills level?

4- Do you think solar, wind, and hydrogen fuel cell power applications will help you as a student to understand math better?

5- Do you think alternative energy would be a good tool to promote science and technology majors in college for women, students of color, and underrepresented students?

6- Would you be interested in Applied Alternative Energy Curriculum promoting Math and Science Education added to your school's current curriculum?

7- Was the overall quality of instruction appropriate and useful for this class?

8- Are you interested in future activities/classes in these or similar subject matter in the Electrical Engineering program at the University of Northern Iowa? 


\section{Conclusion and Recommendations}

The laboratory design was prepared by a graduate student under the supervision of a faculty member. The laboratory experiment was completed in two different session days. During each session, a team of undergraduate students (no more than three students per team) performed the experiment. The results of the survey were used to determine the effect of untraditional teaching method in the electrical circuit class. Students gained experience by connecting multiple systems in parallel for the establishment of the system. The majority of students have found the fuel cell activity relevant to their interests and their mathematical skills. Moreover, students' interest in similar activities can definitely develop their skills and knowledge on alternative energy and other renewable energy topics.

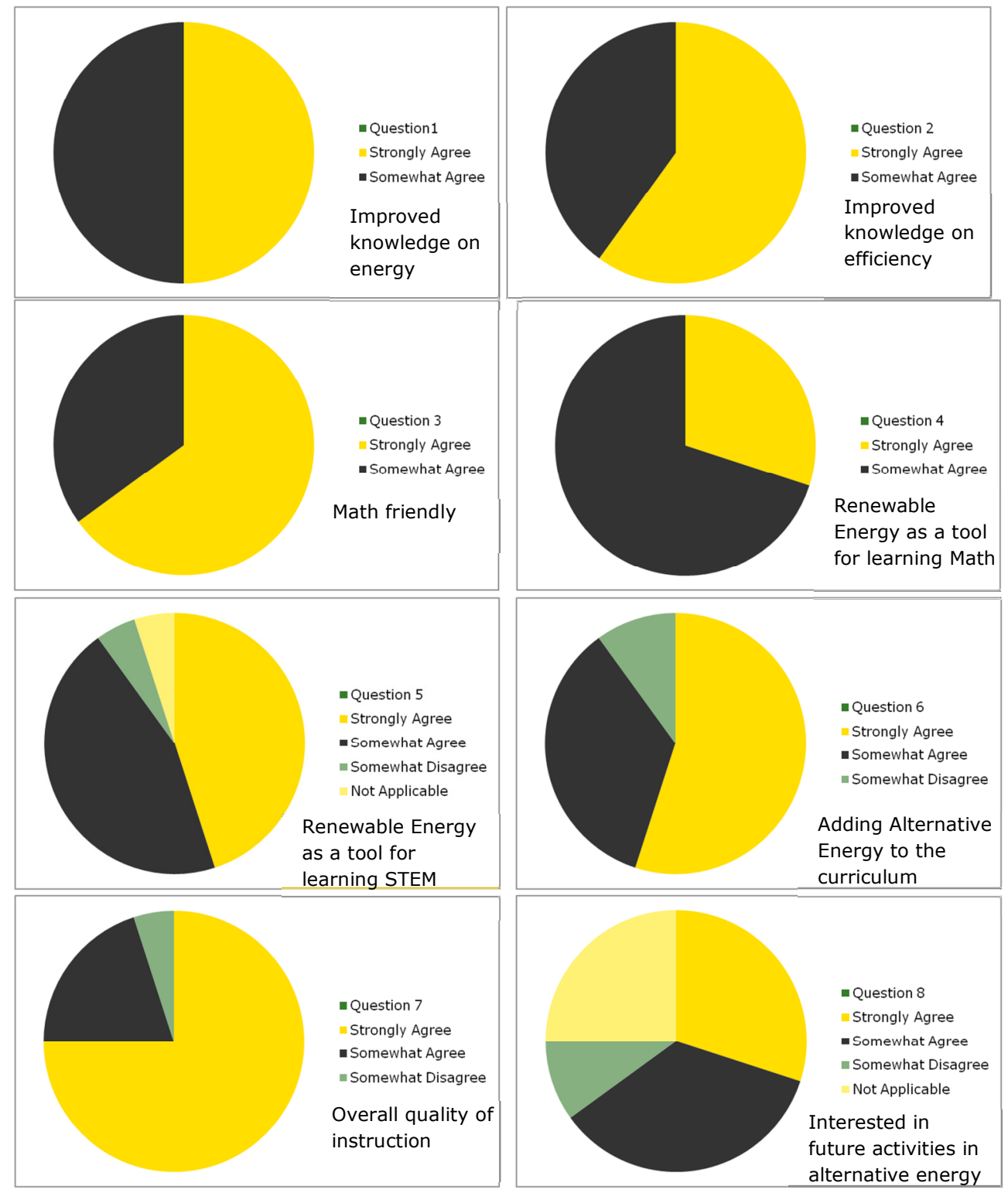

Figure 9: Survey Response 


\section{Conclusion}

Hydrogen fuel cell systems are revolutionary technology that can provide cleaner energy to our environment. Fuel cell systems have the potential in increasing the efficiency of utilizing efficiency since they have proven that they can operate at a better efficiency than any other technology operating on fossil fuels. Thus fuel cells are a promising technology that requires our attention and must be invested by all means. Also fuel cell Systems are one diverse area of engineering that can attract many applications and lead to more research. Therefore, fuel cell Systems must be promoted in education and in our curriculum courses. This experiment was conducted by twenty undergraduate students and supervised by a graduate student. All students showed that they met all the objectives of the activity set by the authors. The survey responses indicate that students' knowledge and skills can be invested in this area. As fuel cell systems can be more complex, more research can be developed to enhance fuel cells efficiency through promoting experience with using fuel cell instrumentation.

\section{Acknowledgements}

Iowa Math and Science Education Partnership (IMSEP) is greatly appreciated for the financial support for the Hydrogen fuel cell trainer and the related curriculum development through a STEM grant titled "MSETI - AREA: Math-Science-Engineering Technology in Iowa on Applied Renewable Energy Areas."

\section{References}

1. Hampden Engineering Corporation. Hampden Model FCTT-1 Fuel Cell Technology Trainer Teacher Maual . East Longmeadow, MA, 2008.

2. U.S. DOE Energy Efficiency and Renewable Energy. Fuel Cell Technology Program. [Online] 2008. https://www1.eere.energy.gov/hydrogenandfuelcells/pdfs/doe_h2_fuelcell_factsheet.pdf.

3. Larminie, James. Fuel Cell Systems Explained. West Sussex, England : John Wiley \& Sons Ltd, 2003.

4. U.S. DOE Energy Efficiency \& Renewable Energy. Fuel Cell Technology. [Online] 2001. https://www1.eere.energy.gov/hydrogenandfuelcells/tech_validation/pdfs/fcm04r0.pdf.

5. FuelCell Energy. Benefits of Fuel Cell Technology. [Online] 2011. http://www.fuelcellenergy.com/benefits-fuelcell-technology.php.

6. Elgowainy, A and Wang, M Q. Fuel Cycle Comparison of Distributed Power Generation Technologies. Argonne, IL : Center for Transportation Research, Argonne National Laboratory, 2008.

7. Pehnt, Martin and Ramesohl, Stefan. Fuel Cells for Distributed Power: Benefits, Barriers, and Prespectives. Belgium : World Wide Fund For Nature, 2003.

8. EG\&G Technical Services. Fuel Cell Handbook. Springfield, VA : National Technical Information Service, 2004.

9. Wankewycz, Taras. [Online] 2011. www.horizonfuelcell.com/files/MinipakPR2010.pdf.

10. Ehsani, Mehrdad, Gao, Yimin and Emadi, Ali. Modern Electric, Hybrid Electric, and Fuel Cell Vehicles. Boca Raton, FL : CRC Press, 2010.

11. University of Northern Iowa Program Outcomes of Electrical Engineering Technology. [Online] 2009. http://www.uni.edu/indtech/eet/outcomes.html. 